\title{
The influence of sintering temperature on the crystal structure, electric and magnetic properties of $\mathrm{Ba}_{(2-\mathrm{x})} \mathrm{Nd}_{(\mathrm{x})} \mathrm{Fe}_{2} \mathrm{O}_{5}$ composite
}

\author{
Patricius Purwanto*, Yunasfi, Ade Mulyawan \\ Center for Science and Technology of Advanced Materials, National Nuclear Energy Agency of Indonesia (BATAN) Kawasan Puspiptek Serpong, \\ Tangerang Selatan 15314, Indonesia \\ * Corresponding author: patricpurwanto@gmail.com
}

\section{Article history}

Received 17 May 2018

Revised 16 August 2018

Accepted 11 October 2018

Published Online 25 June 2019

\begin{abstract}
Magnetic composite material of $\mathrm{Ba}_{(2-x)} \mathrm{Nd}_{(x)} \mathrm{Fe}_{2} \mathrm{O}_{5}$ is used to make electromagnetic wave absorbers. The $\mathrm{Ba}_{(2-x)} \mathrm{Nd}_{(x)} \mathrm{Fe}_{2} \mathrm{O}_{5}$ ( $\mathrm{x}=0$ and 0.1 ) system was synthesized by using solid state reaction method. The $\mathrm{Ba}_{(2-x)} \mathrm{Nd}_{(\mathrm{x})} \mathrm{Fe}_{2} \mathrm{O}_{5}$ system was made with mixture compound of $\mathrm{BaCO}_{3}, \mathrm{Nd}_{2} \mathrm{O}_{3}$ and $\mathrm{Fe}_{2} \mathrm{O}_{3}$ powders with a specific weight ratio, then continued to the milling process and heat treatment at different sintering temperatures. XRD (X-ray diffraction) was conducted for phase identification and to determination of the crystallite size and strain. The study on dielectric and magnetic properties was carried out by using LCR meter and VSM (vibrating sample magnetometer), respectively. The XRD results indicated that the main phase of $\mathrm{Ba}_{2} \mathrm{Fe}_{2} \mathrm{O}_{5}$ was best resulted at $1000{ }^{\circ} \mathrm{C}$. Dielectric properties, such as $\mathrm{AC}$ conductivity and permittivity as a function of the frequency were studied for those best resulted samples. It is found that the substitution of $\mathrm{Nd}^{3+}$ enhances both of the $\mathrm{AC}$ conductivity and permittivity due to the changes of the charge carriers $\left(\sigma_{0}\right)$ and the hoping electron between $\mathrm{Fe}^{2+}$ and $\mathrm{Fe}^{3+}$ ions in the doped system. The $\mathrm{M}-\mathrm{H}$ curves as the results of the magnetic measurement showed the sharp enhancement of the coercivity $(\mathrm{Hc})$ and the slight reduction in the saturation magnetization (Ms) along with the substitution of the $\mathrm{Nd}^{3+}$.
\end{abstract}

Keywords: $\mathrm{Ba}_{(2-\mathrm{x})} \mathrm{Nd}_{(\mathrm{x})} \mathrm{Fe}_{2} \mathrm{O}_{5}, \mathrm{X}$-ray diffraction, AC conductivity, permitivity, magnetic property

\section{INTRODUCTION}

In recent years, the development of hard ferrite-based material has been intensively studied due to its impresive magnetic properties to be applied as permanent magnet material, specifically to be employed to support the industrial technology devices like magnetic heads, inductors component, etc. Barium hexaferrite in the type of $\mathrm{BaFe}_{12} \mathrm{O}_{19}$ is likely to be the most widely used material compared to all types of hard ferrite-based materials. This type is known to possess high value of coercivity $(\mathrm{Hc})$ and magnetic saturation $(\mathrm{Ms})$ with stable chemical properties and corrosion resistance [1]. Unlike the hard type, the soft type of ferrite-based is less popular to be studied or even to be employed for industrial purposes. The soft type is known to has different structures and physical properties compared to the hard type [2].

Barium ferrite with chemical formula $\mathrm{Ba}_{2} \mathrm{Fe}_{2} \mathrm{O}_{5}$ is a soft ferritebased material. It exhibits a superstructure that is isostructural with Brownmillerite $\left(\mathrm{A}_{2} \mathrm{BB}^{\prime} \mathrm{O}_{5}, \mathrm{~A}=\mathrm{Ca}\right.$, Sr, etc. ; $\mathrm{B}=\mathrm{Mn}, \mathrm{Ni}, \mathrm{Al}, \mathrm{Ga}$, etc.) and also has a derivative crystal structure from perovskite structure $\left(\mathrm{ABO}_{3}\right)$. Referring to several studies that have been done, $\mathrm{Ba}_{2} \mathrm{Fe}_{2} \mathrm{O}_{5}$ is normally used as the $\mathrm{CO}_{2}$ absorbents and photocatalysts [3,4]. In other hand, $\mathrm{Ba}_{2} \mathrm{Fe}_{2} \mathrm{O}_{5}$ is also known to exhibit soft magnetic properties with high permittivity value which can be fruitful for other specific purposes such as to be the main compound of the microwave absorbing materials $[5,6]$. In order to create $\mathrm{Ba}_{2} \mathrm{Fe}_{2} \mathrm{O}_{5}$ that is a suitable candidate for microwave absorbing materials, the $\mathrm{Ba}_{2} \mathrm{Fe}_{2} \mathrm{O}_{5}$ needs to has a proper both of the dielectric and magnetic properties. In fact, $\mathrm{BaFe} 2 \mathrm{O} 4$ exhibits several comparable properties compared to those common ferrite materials, such as high capacity of magnetization, highly stable, high coercivity, high permittivity, lowband-gap ferrite material that also can be used as proper candidate of RAM $[7,8,9]$. In addition, the phase formation of $\mathrm{BaFe} 2 \mathrm{O} 4$ requires lower temperature process compared to those common ferrites, this phenomenon can be a huge benefit in industrial process to produce massive RAM products [10]

In this work, the rare-earth metal cation of $\mathrm{Nd}^{3+}$ was substituted to the initial structure of $\mathrm{Ba}_{2} \mathrm{Fe}_{2} \mathrm{O}_{5}$ with the chemical formula of $\mathrm{Ba}(2-$ ${ }_{\mathrm{x})} \mathrm{Nd}_{(\mathrm{x})} \mathrm{Fe}_{2} \mathrm{O}_{5}(\mathrm{x}=0.0$ and 0.1$)$ by using solid state reaction method with different sintering temperatures. Solid state reaction method with mechanical milling was used because of the efficiency, most importantly based on our previous laboratory work as this method has been proven to synthesize similar type of barium ferrite doped by rare earth metal $[10,11]$. The aim of this study was to synthesize the $\mathrm{Ba}_{2} \mathrm{Fe}_{2} \mathrm{O}_{5}$ substituted by $\mathrm{Nd}^{3+}$ and study the phase formation under different sintering temperatures with further analysis on the dielectric properties, such as AC conductivity and permittivity, also magnetic properties of all compositions in room temperature. This work was also a preliminary study to employ a new functional material based on the composition of $\mathrm{Ba}_{(2-\mathrm{x})} \mathrm{Nd}_{(\mathrm{x})} \mathrm{Fe}_{2} \mathrm{O}_{5}$ as a candidate of Microwave or Radar Absorbing Materials (MRAM). 


\section{EXPERIMENTAL}

\section{Materials}

The barium ferrites series with the chemical formula of $\mathrm{Ba}(2-$ $\left.{ }_{x}\right) \mathrm{Nd}_{(\mathrm{x})} \mathrm{Fe}_{2} \mathrm{O}_{5}$ were made from the compound composition of $\mathrm{BaCO}_{3}$ (Aldrich, 99.0\% purity), $\mathrm{Nd}_{2} \mathrm{O}_{3}$ (Aldrich, 99.9\% purity) and $\mathrm{Fe}_{2} \mathrm{O}_{3}$ (Aldrich, $99.9 \%$ purity) with stoichiometry as follows;

$(2-x) \mathrm{BaCO}_{3}+(\mathrm{x} / 2) \mathrm{Nd}_{2} \mathrm{O}_{3}+\mathrm{Fe}_{2} \mathrm{O}_{3}--->\mathrm{Ba}_{(2-x)} \mathrm{Nd}_{(\mathrm{x})} \mathrm{Fe}_{2} \mathrm{O}_{5}+(2-\mathrm{x}) \mathrm{CO}_{2}$

$$
+(5 \mathrm{x} / 4) \mathrm{O}_{2}
$$

\section{Synthesis of $\mathrm{Ba}_{(2-\mathrm{x})} \mathrm{Nd}_{(\mathrm{x})} \mathrm{Fe}_{2} \mathrm{O}_{5}$}

The synthesis process of barium ferrites with solid state reaction method involved several processes such as mixing, sintering, and cooling process. It was started by the mixing process using High Energy Milling (HEM) machine in stainless-steel vial for 2 hours and continued with the sintering process under different temperatures $(800,900$, and 1000) with slow increasing temperature for 1 hour to form the phase formation. The mixture was ground in Agate Mortar so that the powder material could be characterized for further analysis.

All of the samples of $\mathrm{Ba}_{(2-\mathrm{x})} \mathrm{Nd}_{(\mathrm{x})} \mathrm{Fe}_{2} \mathrm{O}_{5}$ were characterized by using XRD Pan Analytical to confirm the phase formation. Vibrating Sample Magnetometer (VSM) type OXFORD (at $1.2 \mathrm{H}$ and \pm 1 Tesla) was used to measure the magnetic properties. Meanwhile, LCR Hioki (3523-50 LCR-Hitester) was used to measure the dielectric properties. This work was also a preliminary study to employ new functional materials based on the composition of $\mathrm{Ba}_{(2-\mathrm{x})} \mathrm{Nd}_{(\mathrm{x})} \mathrm{Fe}_{2} \mathrm{O}_{5}$ as a candidate of Microwave or Radar Absorbing Materials (MRAM).

\section{RESULTS AND DISCUSSION}

\section{The lattice strain and crystallite size as the results of XRD using Williamson-Hall method}

Diffraction patterns of all varied $\mathrm{Ba}_{(2-\mathrm{x})} \mathrm{Nd}_{(\mathrm{x})} \mathrm{Fe}_{2} \mathrm{O}_{5}(\mathrm{x}=0.0$ and 0.1 ) which have been synthesized by using solid state reaction method are shown in the Figure 1. As shown from Figure 1, it could be noticed for the main phase of $\mathrm{Ba}_{2} \mathrm{Fe}_{2} \mathrm{O}_{5}$ (referring to JCPDS file No.39-1296) and the secondary phase of $\mathrm{Fe}_{2} \mathrm{O}_{3}$ (referring to JCPDS file No.32-0469), and as well as for $\mathrm{BaO}$ phase (referring to JCPDS file No.01-0746). The $\mathrm{Ba}_{2} \mathrm{Fe}_{2} \mathrm{O}_{5}$ phase increases along with the increase of sintering temperature for both compositions.
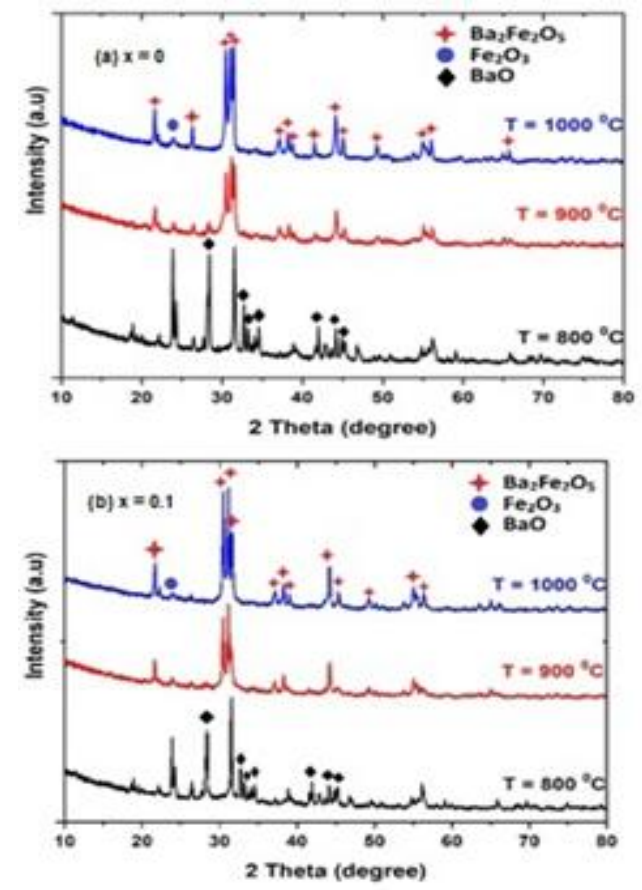

Fig. 1 X-ray diffraction pattern of $\mathrm{Ba}_{(2-x)} \mathrm{Nd}_{(x)} \mathrm{Fe}_{2} \mathrm{O}_{5}$ series with different temperatures for (a) $\mathrm{x}=0$, and $(\mathrm{b}) \mathrm{x}=0.1$ composition.
It can be seen from the main peaks for the phase of $\mathrm{Ba}_{2} \mathrm{Fe}_{2} \mathrm{O}_{5}$ in $30.40 \pm 0.02^{0}$ until $32.50 \pm 0.02^{0}$ that correspond to the index miller of (040), (027), and (204), the shape of the peak is more shifted compared to other temperature treatment which indicates that $1000^{\circ} \mathrm{C}$ is the most appropriate sintering temperature to form $\mathrm{Ba}_{2} \mathrm{Fe}_{2} \mathrm{O}_{5}$ in both compositions.

In this work, the crystallite parameters were carried out by using Wiliamson-Hall method. According to previous studies, WiliamsonHall method is more appropriate to determine the crystallite size and lattice strain due to the ability to calculate and determine the distinct of the diffraction angle for the dissociation of crystallite size and strain of the broadening peaks $[12,13]$. The crystallite size (D), the $2 \Theta$ and half peak width (FWHM) of all compositions were calculated using Igor Lorentzian program. The calculation of the crystallite size and lattice strain using Williamson-Hall method could be derived from the equation as follows:

$$
\beta_{\text {hkl }} \cos \theta=K \cdot N D+4 \varepsilon \sin \theta
$$

where : $\mathrm{K}$ is constant, $\lambda$ is wavelength of $\mathrm{Cu}, \mathrm{D}$ is crystalite size, $\varepsilon$ is crystal strain and $\beta_{\mathrm{hkl}}$ is FWHM (Full Wide Half Maxium). From Equation (1), the linear line was plotted between the $\beta \cos \theta$ with respect to the $\sin \theta$ for the 6 highest main peaks of $\mathrm{Ba}_{2} \mathrm{Fe}_{2} \mathrm{O}_{5}$ as shown in Figure 2(a) and Figure 2(b). The grain size and lattice strain of each composition with different temperatures were calculated from the slope and y-intercept of the linear line.
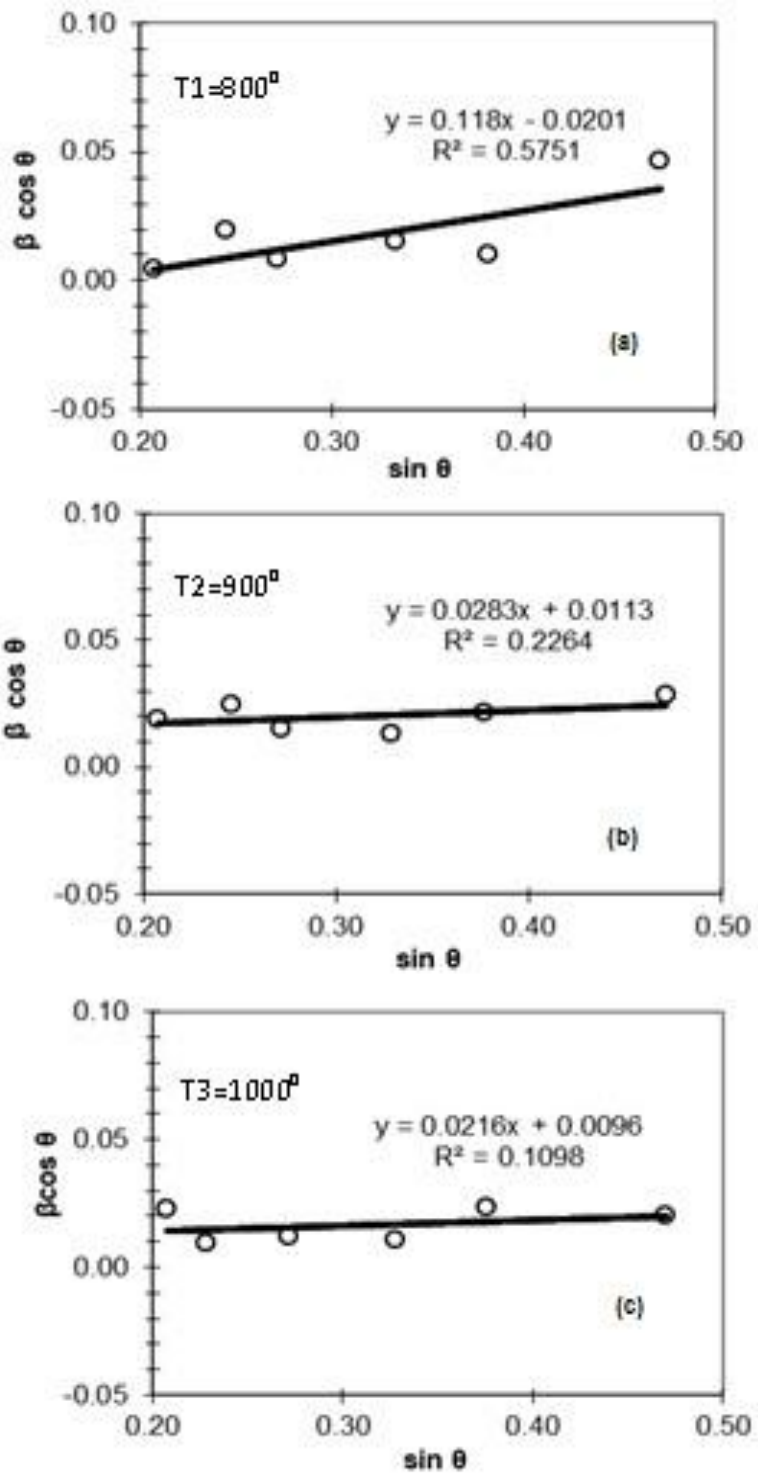

Fig. 2(a) Williamson-Hall plots of $\mathrm{Ba}_{(2-x)} \mathrm{Nd}_{(x)} \mathrm{Fe}_{2} \mathrm{O}_{5}$ for $x=0$ at different temperatures a) $\mathrm{T}_{1}=800{ }^{\circ} \mathrm{C}$ b) $\left.\mathrm{T}_{2}=900{ }^{\circ} \mathrm{C} \mathrm{c}\right) \mathrm{T}_{3}=1000{ }^{\circ} \mathrm{C}$. 

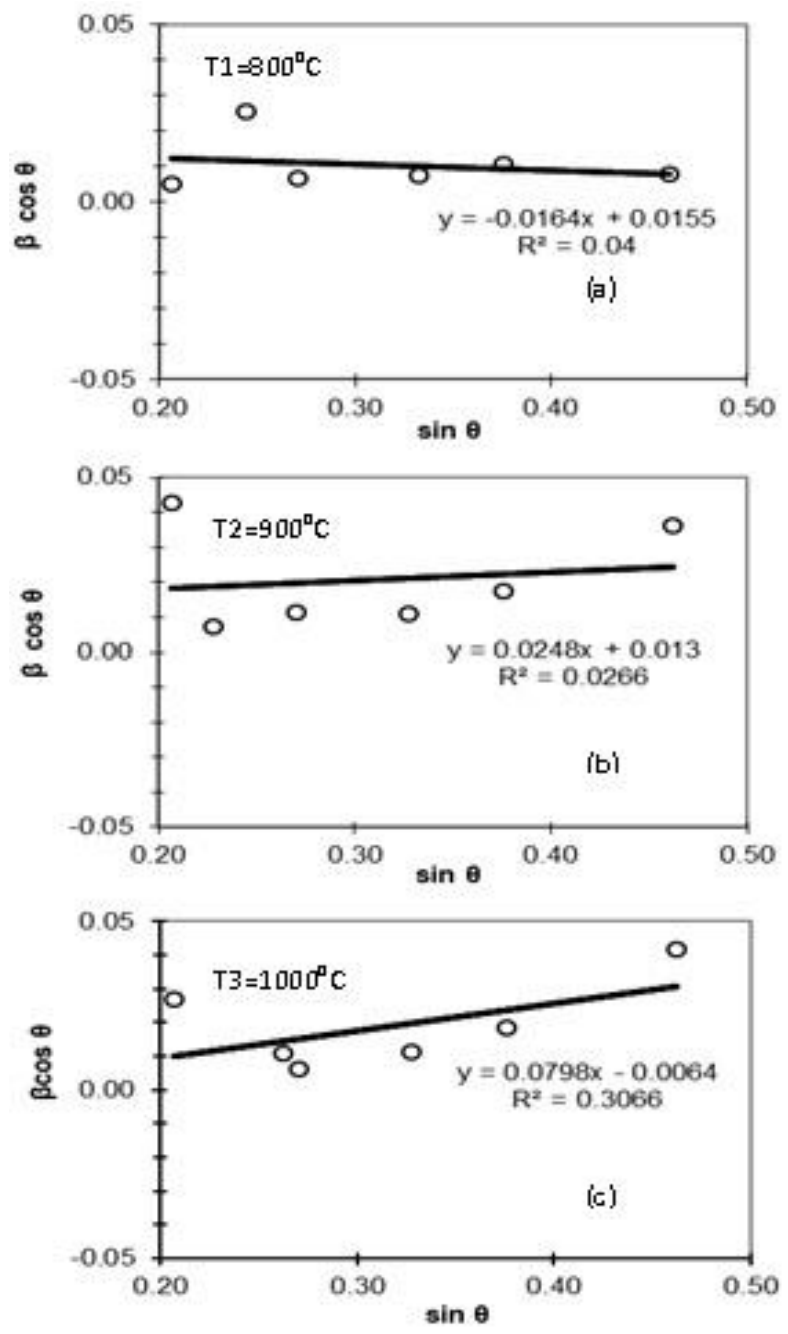

Fig. 2(b) Williamson-Hall plots of $\mathrm{Ba}_{(2-x)} \mathrm{Nd}_{(x)} \mathrm{Fe}_{2} \mathrm{O}_{5}$ for $\mathrm{x}=0.1$ at different temperatures a) $\mathrm{T}_{1}=800{ }^{\circ} \mathrm{C}$ b) $\left.\mathrm{T}_{2}=900^{\circ} \mathrm{C} \mathrm{c}\right) \mathrm{T}_{3}=1000^{\circ} \mathrm{C}$.

The correlation between crystalite size and strain from the plots that resulted using Williamson-Hall method (in Figure 2) is represented in Table 1 and Figure 3. In Table 1 and Figure 3(b) for the compositin of $\mathrm{x}=0.1$, the increasing temperature would also increase both of the strain and crystallite size. In Table 1 and Figure 3 (a) for the compositin of $x=0$, it could be noticed that along with the increasing sintering temperature, the crystallite size was also increased, making the lattice strain to decrease. According to the research done by Kanagaraj et al. (2014), this phenomenon may be attributed to the peak broadening along with the increassing temperature [12]. Referring to the formation of $\mathrm{Ba}_{2} \mathrm{Fe}_{2} \mathrm{O}_{5}$ as the main phase from the results of XRD, it can be concluded that $1000{ }^{\circ} \mathrm{C}$ is the most proper sintering temperature to synthesize the $\mathrm{Ba}(2-\mathrm{x}) \mathrm{Nd}_{(\mathrm{x})} \mathrm{Fe}_{2} \mathrm{O}_{5}$. Thus, for following characterization to determine dielectric properties and magnetic properties, it will only be focusing on those samples.

Table 1 The results of the crystallite size (D) and the lattice strain for all $\mathrm{Ba}_{(2-x)} \mathrm{Nd}_{(\mathrm{x})} \mathrm{Fe}_{2} \mathrm{O}_{5}$ compositions at different temperatures treatment.

\begin{tabular}{cccc}
\hline $\begin{array}{c}\text { Composition of } \\
\mathbf{B a}_{(2-\mathrm{x})} \mathrm{Nd}_{(\mathbf{x})} \mathrm{Fe}_{2} \mathbf{O}_{5}\end{array}$ & $\begin{array}{c}\text { Temperature } \\
\text { in }{ }^{0} \mathbf{C}\end{array}$ & $\begin{array}{c}\text { Crystallite } \\
\text { size (D) in } \mathbf{~ n m}\end{array}$ & $\begin{array}{c}\text { strain } \\
(\boldsymbol{\varepsilon})\end{array}$ \\
\hline \multirow{2}{*}{$\mathbf{x = 0}$} & 800 & 6.90 & 5.92 \\
& 900 & 13.37 & 1.48 \\
& 1000 & 14.46 & 1.02 \\
\hline \multirow{2}{*}{$\mathbf{x = 0 . 1}$} & 800 & 8.95 & 0.82 \\
& 900 & 11.62 & 1.24 \\
& 1000 & 21.68 & 3.95 \\
\hline
\end{tabular}
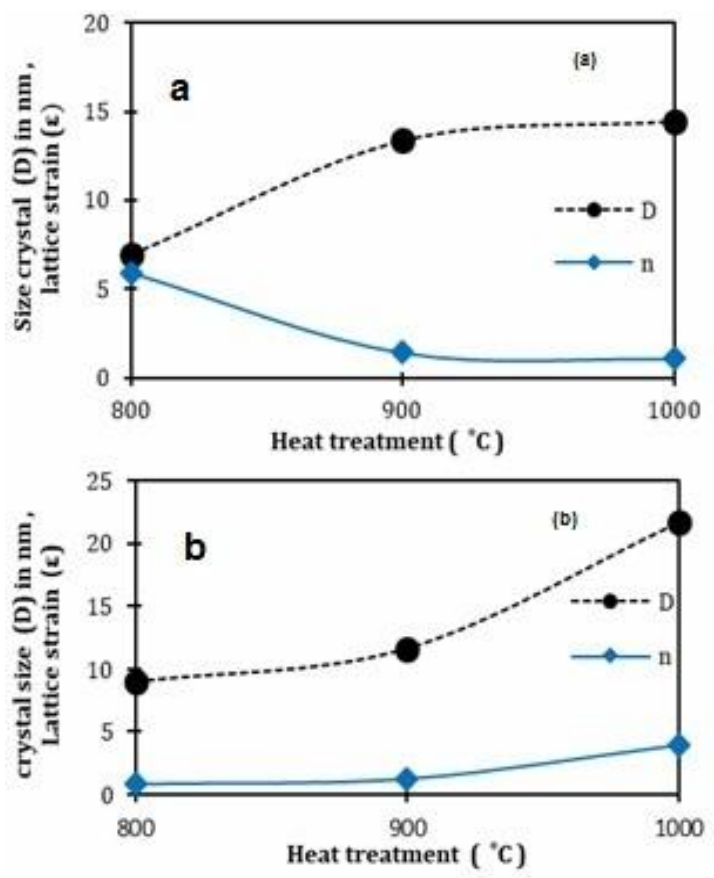

Fig. 3 Curve of crystallite size (D) and strain $(\eta)$ under different sintering temperatures of $\mathrm{Ba}_{(2-x)} \mathrm{Nd}_{(\mathrm{x})} \mathrm{Fe}_{2} \mathrm{O}_{5}$ series for (a) $\mathrm{x}=0$, and (b) $\mathrm{x}=0.1$.

\section{Frequency-dependence of dielectric properties, AC conductivity and permittivity}

The result of the conductivity value is shown in Figure 4 where the AC conductivity was plotted in the function of $\log$ frequency $(\mathrm{Hz})$ with respect to the $\log$ of the conductivity value $(\mathrm{S} / \mathrm{sm})$ in the range frequency started from $0.1 \mathrm{~Hz}$ to $1000 \mathrm{~Hz}$. The calculation of the AC conductivity value was determined by using Padma Kumar model [14]. The details of this model equation were shown as follow:

$$
\log \sigma=\log \sigma_{0}+s \log f
$$

where $\sigma$ is an $\mathrm{AC}$ conductivity $(\mathrm{S} / \mathrm{cm})$ as the results of the measurement, $\mathrm{s}$ is the exponential factor, and $\sigma_{o}$ is the value of the conductivity that does not depend on the frequency, the $\sigma_{o}$ itself is related to the charge carriers of the composition. The results of the measurement of $\sigma_{0}$ for each sample are shown in Table 2 .

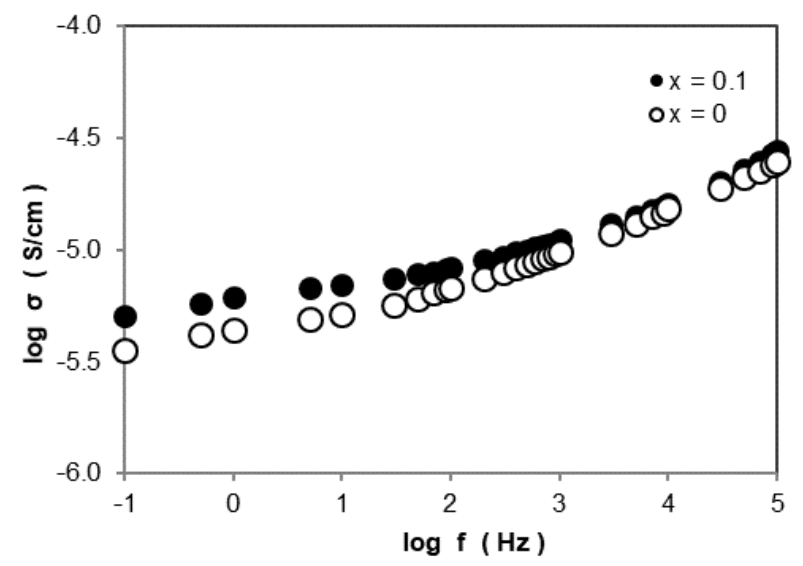

Fig. 4 The $A C$ conductivity value for $\mathrm{Ba}_{(2-x)} \mathrm{Nd}_{(x)} \mathrm{Fe}_{2} \mathrm{O}_{5}$ (a) $\mathrm{x}=0$, and (b) $\mathrm{X}=0.1$ composition with sintering temperature at $1000{ }^{\circ} \mathrm{C}$.

Figure 4 shows the results of AC conductivity with ranging frequency at room temperature. In the case of the electrical conduction in ferrite system, the conduction mechanism can be understood by the model of hoping electron between $\mathrm{Fe}^{2+}$ and $\mathrm{Fe}^{3+}$ ions. As the frequency of the applied system is increased, it will enhance the hopping frequency of the electrons in the mobility of the charge barriers and finally lead into the gradual increase of the AC 
conductivity along with the increasing frequency $[15,16]$. It also can be noticed that the small substitution of the rare earth ions to the initial structure of the $\mathrm{Ba}_{2} \mathrm{Fe}_{2} \mathrm{O}_{5}$ can increase the conductivity either under the influence of the frequency (Figure 4) or at the current frequency of $0.0 \mathrm{~Hz}$ (Table 2). In terms of the $\mathrm{Nd}^{3+}$ ions substitution, as the rare earth ions partially replaces the occupation of the $\mathrm{Ba}^{2+}$ ions in initial structure, it changes the charge carrier of the system $\left(\sigma_{0}\right)$ that leads into the change of the drift mobility and thereby enhancing the charge hopping of the new system.

Table 2 The results of the $\sigma_{0}$ for $\mathrm{Ba}_{(2-x)} \mathrm{Nd}_{(x)} \mathrm{Fe}_{2} \mathrm{O}_{5}(x=0$ and 0.1$)$ at $\mathrm{T}=1000^{\circ} \mathrm{C}$.

\begin{tabular}{cc}
\hline $\begin{array}{c}\text { Composition of } \\
\mathrm{Ba}_{(2-\mathrm{x})} \mathrm{Nd}_{(\mathrm{x})} \mathrm{Fe}_{2} \mathrm{O}_{5}\end{array}$ & $\sigma_{0}(\mathrm{~S} / \mathrm{cm})$ \\
\hline $\mathrm{x}=0.0$ & $3.43 \times 10^{-5}$ \\
$\mathrm{x}=0.1$ & $7.92 \times 10^{-6}$ \\
\hline
\end{tabular}

Figure 5 shows the plot of the permittivity value with respect to the log frequency for all compositions. Similar with the results of the $\mathrm{AC}$ conductivity, the composition of $\mathrm{x}=0.1$ showed a higher permittivity value compared to the undoped composition $(\mathrm{x}=0)$, it may be attributed to the difference in charge carrier of each value of the permittivity that decreases along with the increase of the frequency. Referring to the Maxwell-Wagner type polarization and Koop's phenomenological theory of dielectrics, this phenomenon can be understood because in low frequency region, the excitation of bound electrons and lattice vibration along with space charge polarization are active, making electric dipoles to follow the frequency and finally leading into the high value of the permittivity. In higher frequency range, the electric dipoles are not able to follow the applied frequency and remain constant for all compositions. This result is corresponded to other research study done by Pandya et al. who studied the electrical properties of Barium Strontium Titanate [17].

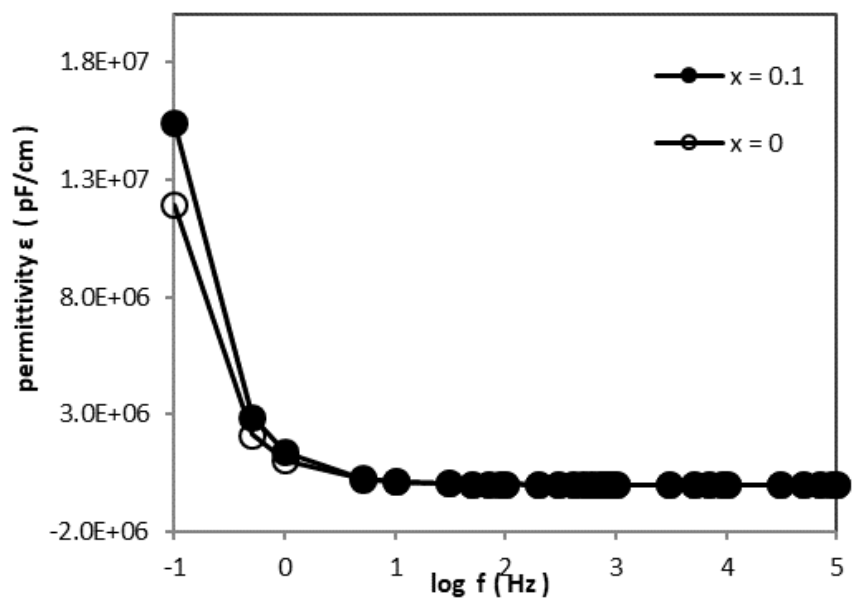

Fig. 5 The results of the permittivity value for $\mathrm{Ba}_{(2-x)} \mathrm{Nd}_{(x)} \mathrm{Fe}_{2} \mathrm{O}_{5}$ (a) $x=$ 0 , and $(b) x=0.1$ composition with sintering temperature at $1000^{\circ} \mathrm{C}$.

\section{The analysis of the magnetic properties}

The magnetization hysteresis curve of all $\mathrm{Ba}(2-\mathrm{x}) \mathrm{Nd}_{(\mathrm{x})} \mathrm{Fe}_{2} \mathrm{O}_{5}$ series at room temperature showed hard and ferromagnetic hysteresis loops as shown in Figure 6 with the details values of each parameteres are listed in Table 3. The magnetic measurements presented a significant increase in coercivity $(\mathrm{Hc})$ as the results of the substitution of $\mathrm{Nd}^{3+}$ cations into the initial system of $\mathrm{Ba}_{2} \mathrm{Fe}_{2} \mathrm{O}_{5}$. The $\mathrm{Hc}$ values were increased from 582 Oe in undoped composition $(x=0)$ Oe to $1770 \mathrm{Oe}$ in the composition of $\mathrm{x}=0.1$ while the value of the Magnetization saturation (Ms) and Magnetization remanence $(\mathrm{Mr})$ were found to decrease from $3.58 \mathrm{emu} / \mathrm{gr}$ and $1.16 \mathrm{emu} / \mathrm{gr}$ to $1.45 \mathrm{emu} / \mathrm{gr}$ and 0.78 emu/gr, respectively. The significant increase of the coercivity is highly attributed to the substitution of $\mathrm{Nd}^{3+}$ that influences the total magnetocrystalline anisotropy as the results of the magnetic dillution phenomenon. Magnetic dillution phenomenon is occurred when more $\mathrm{Fe}^{3+}$ cations are changing to become $\mathrm{Fe}^{2+}$ in $2 a$ site due to the substitution of $\mathrm{Nd}^{3+}$, leading to higher magnetocrystalline anisotropy and coercivity, this phenomenon is commonly occured for the ferrite substituted by rare-earth metal compositions [18]. Simultaneously, the decrease of the Ms and $\mathrm{Mr}$ values is also influenced by the magnetic dillution phenomenon by disrupting the superexchange interaction between the alignment of $\mathrm{Fe}^{3+}$ cations due to the substitution of $\mathrm{Nd}^{3+}$, and considerably lowering the magnetization saturation and remanence in the composition of $\mathrm{x}=0.1$.

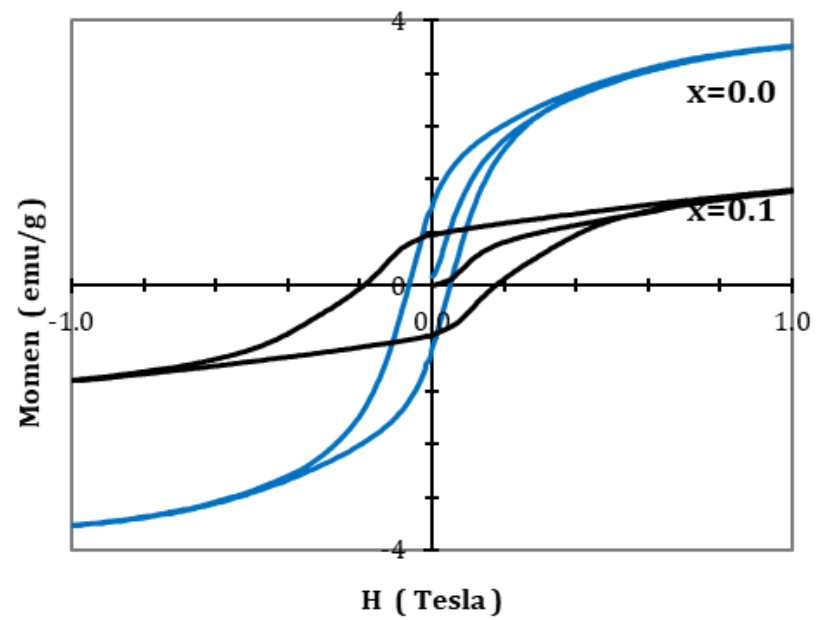

Fig. 6 Magnetization hysteresis curve of $\mathrm{Ba}_{(2-x)} \mathrm{Nd}_{(x)} \mathrm{Fe}_{2} \mathrm{O}_{5}$ (a) $x=0$, and (b) $x=0.1$ composition with sintering temperature at $1000^{\circ} \mathrm{C}$.

Table 3. The results of the magnetic parameters for $\mathrm{Ba}_{(2-x)} \mathrm{Nd}_{(x)} \mathrm{Fe}_{2} \mathrm{O}_{5}$ $(\mathrm{x}=0$ and 0.1$)$ at $\mathrm{T}=1000^{\circ} \mathrm{C}$.

\begin{tabular}{ccccc}
\hline $\begin{array}{c}\text { Composition of } \\
\mathrm{Ba}_{(2-\mathrm{x})} \mathrm{Nd}_{(\mathrm{x})} \mathrm{Fe}_{2} \mathrm{O}_{5}\end{array}$ & $\mathrm{Ms}(\mathrm{emu} / \mathrm{g})$ & $\begin{array}{c}\mathrm{Mr} \\
(\mathrm{emu} / \mathrm{g})\end{array}$ & $\mathrm{Hc}(\mathrm{Oe})$ \\
\hline $\mathrm{X}=0$ & 3.58 & 1.16 & 582 \\
$\mathrm{X}=0.1$ & 1.45 & 0.78 & 1770 \\
\hline
\end{tabular}

\section{CONCLUSION}

The series of barium ferrite doped by rare earth cations $\left(\mathrm{Nd}^{3+}\right)$ in the form of $\mathrm{Ba}_{(2-\mathrm{x})} \mathrm{Nd}_{(\mathrm{x})} \mathrm{Fe}_{2} \mathrm{O}_{5}(\mathrm{x}=0$ and 0.1$)$ under different sintering temperatures have been succesfully synthesized by solid state reaction method. The result of XRD showed that phase formation of $\mathrm{Ba}_{2} \mathrm{Fe}_{2} \mathrm{O}_{5}$ resulted is best in $1000{ }^{\circ} \mathrm{C}$ for both compositions. The analysis of the $\mathrm{AC}$ conductivity and permittivity with respect to the frequency has been evaluated and showed that the increasing content of $\mathrm{Nd}^{3+}$ cations will increase the value of the AC conductivity and its permittivity, regarding to the hoping electron between $\mathrm{Fe}^{2+}$ and $\mathrm{Fe}^{3+}$ ions and the changes of the charge carrier $\left(\sigma_{0}\right)$. The magnetic properties of the sample confirmed that all the compositions have a ferromagnetic behaviour. The coercivity value of the $\mathrm{Ba}_{(2-\mathrm{x})} \mathrm{Nd}_{(\mathrm{x})} \mathrm{Fe}_{2} \mathrm{O}_{5}$ in the composition of $\mathrm{x}=0.1$ significantly improved due to the presence of the $\mathrm{Nd}^{3+}$ cations that cause the changes of the magnetocrystalline anisotrophy as the results of the magnetic dillution phenomenon in the system.

As for the application as microwave or radar absorbing materials, the dielectric and magnetic properties are the most important factors to be considered. The next study will be focused on the Microwave or Radar Absorbing Material (MRAM) properties of the $\mathrm{Ba}_{(2-}$ ${ }_{\text {x) }} \mathrm{Nd}_{(\mathrm{x})} \mathrm{Fe}_{2} \mathrm{O}_{5}$ system.

\section{ACKNOWLEDGEMENT}

This work was financially supported by research insentive funds from Center for Science and Technology of Advanced Materials 
- National Nuclear Energy Agency of Indonesia (DIPA PSTBM-

BATAN) 2015-2019.

\section{REFERENCES}

[1] Sebayang, P. and Muljadi. 2011. Kajian struktur mikro terhadap sifat magnetik pada magnet permanen $\mathrm{Ba}_{0.6} \mathrm{Fe}_{2} \mathrm{O}_{3}$. Telaah Jurnal Ilmu Pengetahuan dan Teknologi 29(2), 55-62.

[2] Molaei, M. J., Ataie, A., Raygan, S., Picken, S. J., Mendes, E., Tichelaar, F. D. 2012. Synthesis and characterization of $\mathrm{BaFe}_{12} \mathrm{O}_{19} / \mathrm{Fe}_{3} \mathrm{O}$ and $\mathrm{BaFe}_{12} \mathrm{O}_{19} / \mathrm{Fe} / \mathrm{Fe}_{3} \mathrm{O}_{4}$ magntic nanocomposite. Powder Technology 211, 292-295.

[3] Fujishiro, F., Fukasawa, K., and Hashimoto, T. 2011. $\mathrm{CO}_{2}$ absorption and desorption properties of single phase $\mathrm{Ba}_{2} \mathrm{Fe}_{2} \mathrm{O}_{5}$ and analysis of their mechanism using thermodynamic calculation, Journal American Ceramic Society 94(11), 3675-3678.

[4] Fujishiro, F., and Nakazawa, Y. 2014. Reversible reaction with $\mathrm{CO}_{2}$ and control of $\mathrm{CO}_{2}$ absorption/desorption properties of $\mathrm{Ba}_{2}\left(\mathrm{Fe}_{1^{-} \mathrm{x}} \mathrm{In}_{\mathrm{x}}\right)_{2} \mathrm{O}_{5}$ solid solutions, Journal American Ceramic Society 97(10), 3034-3036.

[5] Duggal, S., and Aul, G. D. 2014. Review on effect of electric permittivity and magnetic pearbility over microwive absorbing materials at low frequencies. International Journal of Engineering and Advance Technology 3(5), 12-19.

[6] Priyono, and Manaf, A. 2010. Material magnetik barium heksaferit tipeM untuk material anti radar pada frekuensi S-band. Jurnal Sains Materi Indonesia 11(2), 75-78.

[7] Singh, A., Narang, S. B., Singh, K., Pandey, O. P., Kotnala, R. K. 2010 Electrical and magnetic properties of rare earth substituted strontium hexaferrites. Journal of Ceramic Processing Research 11(2), 241-249.

[8] Katoch, A., Singh, T., Sandhu, B. S. 2013. Influence of doping of rare earth ion $(\mathrm{RE}=\mathrm{La})$ on structural, electrical and dielectric properties of SrM-hexaferrite. International Journal of Research in Advent Technology 1(5),456-465.

[9] Singh, N. K., Kumar, P., Radheshyam, R. 2011. Comparative study of structure, dielecctric and electrical behavior of $\mathrm{Ba}\left(\mathrm{Fe}_{0.5} \mathrm{Nb}_{0.5}\right) \mathrm{O}_{3}$ ceramics and their solid solution with $\mathrm{BaTiO}_{3}$. Advance Materials Letters 2(3), 200-205.

[10] Mulyawan, A., Adi, W. A., Yunasfi. 2018. Raman spectroscopy study, magnetic and microwave absorbing properties of modified barium strontium monoferrite $\mathrm{Ba}_{(1-\mathrm{x})} \mathrm{Sr}_{(\mathrm{x})} \mathrm{Fe}_{2} \mathrm{O}_{4}$. Malaysian Journal of Fundamental and Applied Sciences 14(1), 73-77.

[11] Srikrishna Ramya, S. I., Mahadevan, C. K. 2014. Effect of calcination on the electrical properties and quantum confinement of $\mathrm{Fe}_{2} \mathrm{O}_{3}$ nanoparticle. International Journal of Research in Engineering and Technology 3(3), 570-573.

[12] Kanagaraj, M., Sathishkumar, P., Selvan, G. K., Kokila, I. P., Arumugam, S. 2014. Structural and magnetic properties of $\mathrm{CuFe}_{2} \mathrm{O}_{4}$ asprepared and thermally treated spinel nanoferrites. Indian Journal Pure \& Applied Physic 52(2), 124-130.

[13] Khorsand Zak, A., Majid, W. H. A., Abrishami, M. E., Yousefi, R., 2011. $\mathrm{X}$-ray analysis of $\mathrm{ZnO}$ nanoparticle by Williamson-Hall and size-strain plot method. Solid State Science 13(1), 251-258.

[14] Padma, P., and Yashonat, Y. 2006. Ionic conduction in the solid state. Journal of Chemical Science 118(1), 134-154.

[15] Arunkumar, A., Vanidha, D. Oudayakumar, K. Rajagopan, S., Kannan, R. 2013. Metallic magnetism and change of conductivity in the nano to bulk transition of cobalt ferrite. Journal Applied Physics 114,183905.

[16] Nongjai, R., Khan, S., Asokan, K., Ahmed, H., Khan, I. 2012. Magnetic and electrical properties of In doped cobalt ferrite nanoparticles. Journal Applied Physics 112(8), 084321.

[17] Pandya, R. J., Joshi, U. S., Caltun, O. F. 2015. Microstructural and electrical properties of barium strontium titanate and nickel zinc ferrite composites. Procedia Materials Science 10, 168-175.

[18] Cong-Ju, L., Bin, W., Jiao-Na, W. 2012. Magnetic and microwave absorbing properties of electrospun $\mathrm{Ba}_{(1-\mathrm{x})} \mathrm{La}_{(\mathrm{x})} \mathrm{Fe}_{12} \mathrm{O}_{19}$ nanofibers. Journal of Magnetism and Magnetic Materials 324(7), 1305-1311. 